\title{
An Assessment of the Effectiveness of Self-Service Technology in a University Enviroment: The Case of University of the Witwatersrand
}

\author{
Yandisa Ngcwabe \\ Department of Marketing, University of the Witwatersrand \\ Email: yaya.qdee@gmail.com \\ Norman Chiliya \\ Department of Marketing, University of the Witwatersrand \\ Private Bag 3, Wits, 2050 \\ Email: norman.chiliya@wits.ac.za
}

\section{Doi:10.5901/mjss.2014.v5n14p413}

\section{Abstract}

\begin{abstract}
Self-service is basically a method of serving oneself in business-related organisation without the help of an employee. With the exponential increase of the technology, service companies adopt Self-Service Technologies (SSTs) as their innovative tools to create value. A great amount of research has focused on customers' perspectives of adopting SSTs using factors of SST adoption, attitudes and intentions toward to use the SST. However, studies on the adoption of SSTs at University institutions particularly in South Africa has not been explored extensively. The notion of self-service is positioned as an important part of the overall system where students are to view, input and modify administrative and financial information on themselves, their work and their courses. Convenience is a major benefit of self-service technology and individuals that are not techno savvy or lack technological resources cannot reap the benefits of SSTs to its fullest potential. The study evaluates the attitudes and perceptions that students have regarding SSTs. This research consisted of a self-administered quantitative research questionnaire, which was initially tested using two pilot studies of 30 and 20 respondents respectively. The questionnaire was distributed at the University of the Witwatersrand (Wits) to a sample group of 380 respondents between the ages of 18 to 30 . The data collected was analysed using statistical analysis to examine the relationships between the variables in the research model. Results indicate that some students still value face-to-face service encounters, others lack resources to use SSTS and the effect of self-efficacy limits other students from using SSTs to their fullest potential. Perceived waiting time also has a great influence on the actual use and frequency of SSTS.
\end{abstract}

Keywords: Self- service technology, university environment

\section{Introduction}

The developments in technology have made it possible for businesses and firms that provide services to integrate many different types of technology systems into the execution of their services (Curran \& Meuter, 2005). As a result of the growth in technology, there has been a decrease in cost of the actual execution and use of technology, which present prospective changes for primary methods that are currently being used in business (Curran \& Meuter, 2005). The world has moved from a product orientated economy, to a service oriented economy and there is quite a reasonable explanation for this shift (Oliva \& Kallenberg, 2003). The advancement in technology accompanied by the change in times has dramatically altered the modern day consumer's needs (Oliva \& Kallenberg, 2003).

Bitner, Ostrom and Meuter (2002) further state that technology in the self-service industry help companies in decreasing costs, carrying out customers' demands, increasing customer satisfaction and enlarging new distribution channels .A trend that is developing in CRM is the usage of self-service and the rise in technology works best here as services become more efficient to use (Bitner, Ostrom, \& Meuter, 2002). Initially consumers where happy with other people helping them in achieving the intended service until service providers failed consumers in providing a service that completely satisfied them according to their individual needs and wants, but are self-service technologies affective in performing a better job than one-on-one interactions? (Bitner, Ostrom, \& Meuter, 2002). The focus of this study was on the use of self-service in the higher education environment.

Financial benefits are a major factor, but universities have also noticed that there is a need to apply principles of effectively managing their services and increasing customer satisfaction (Browne, Kaldenberg, Browne \& Brown, 1998). 
Universities' main goal is to improve services to students and the faculty and to also remain financially viable by paying employees and service providers. The university's focal point is mainly on the administrative processes for instance the admission system, payment of fees and regular student service which includes buying food. Students' top priority when looking for an institution to enrol at is the academic dimensions it offers and their reputation but within these considerations students also look at the resources that are offered and how proficient and easy to use the systems will be when they decide to study at that particular institution (Browne, Kaldenberg, Browne \& Brown, 1998).

The SST system at Wits University has gone through a number of developments over the years. It is very crucial to get to a point where research is conducted to evaluate why previous SST systems have not been entirely successful. What value does a successful SST in every area of need have towards students? There are so many opportunities of improvement which the university can work at attaining. Students on campus make use of services such as registration at the beginning of the year, bus systems that travel to other Wits campuses and other locations; they need an efficient operating system in this case, booking university residence meals, borrowing books from the library, applying for courses and course amendments, checking for any important information and paying for their tuition.

The current generation of students mostly consists of the "microwave generation", where consumers seek to have everything done instantaneously, effortlessly and expect to receive it in high quality (Kwon, 2010). Wits recently launched a new Student Information Management System (SIMS) on Monday 4 March 2013 executed by the University to replace the previous Oracle Student System (OSS). The question at hand is what has caused the failure to meet students who are the consumers' complete needs in the past? There are still long queues during registration, residential students are still missing their meals, and there are still problems causing complicated payment methods. To sum it up, there definitely needs to be research done to discover whether a convenient and high quality system is necessary and exactly what consumers (students) really want to have at their disposal to benefit them on campus.

\subsection{Problem Statement}

The purpose of this study was to assess the value that self-service technology potentially has at the University of the Witwatersrand. The focus is on students at this institution because students seek improved ways of getting their work and administration related issues sorted. Numerous changes have taken place with the infrastructure of the SST system at the university, from using various types of systems such as Oracle, WebCT and Sakai (e-learning). This has resulted in resources and priceless time being wasted. SIMS experienced problems as senators expressed their dissatisfaction with a few self-service processes (Kgosana, 2013). It is quite evident that the system has gone through a few glitches, hence the need to evaluate the effectiveness of the overall system.

In the service market, convenience is important and quite necessary in this fast paced world, yet the implementation of making use of technology in services is still experiencing a lot of resistance (Berry, Seiders \& Grewal, 2002). The research investigated why and how this resistance occurred through past studies done and through the findings gathered from the questionnaires. Widespread academic research has investigated the features of interpersonal communications between service providers and customers, but not at much research was conducted in the same capacity regarding customer interactions with the technological line (Meuter, Ostrom, Roundtree \& Bitner, 2000). No past research was conducted on the success or failure of SSTs systems in the university setting.

It would be beneficial for students to have the option of having improved services throughout their years of study to make life easier for them but another issue at hand is to find solutions to the glitches in service technology at the university. Students have faced traumatic experiences in the past which have even come at the expense of injuries and losing parents' lives, which is a far greater reason to view the SST system efficiency. More banks are turning to selfservice technology to provide customers with many channels to access products and services (Meuter, Bitner, Ostrom, \& Brown, 2005) but what about increasing this system at an education institution such as Wits.

\subsection{Research Objectives}

The primary objective of this research was to assess the actual effectiveness of self-service technologies (SSTs) implemented at the University of the Witwatersrand in the services that students make use of and major administration systems which were and are currently still being improved.

The secondary objectives are to:

- Determine whether there is a need for SSTs at the University of the Witwatersrand.

- Evaluate the attitudes and perceptions consumers have regarding SSTs.

- Establish whether students prefer using self-service terminals over having face-to-face interaction services. 
- Determine what factors influence consumers to adapt to the SSTs.

\subsection{Contribution}

This research would be of great benefit to Wits University itself in efforts to improve the self-service system that was implemented. It could also act as a benchmark for other Universities in envisioning a developed system for their students, although they would continue to remain a competition to Wits University. The study adds to academic literature in developing additional information to the subject at hand.

\section{Theoretical Model and Hypotheses}

The adapted technology adoption model is illustrated in Figure 1. This adapted model was used to examine the effectiveness of Self-Service Technology at the University of the Witwatersrand.

Figure 1: The adapted technology adoption model

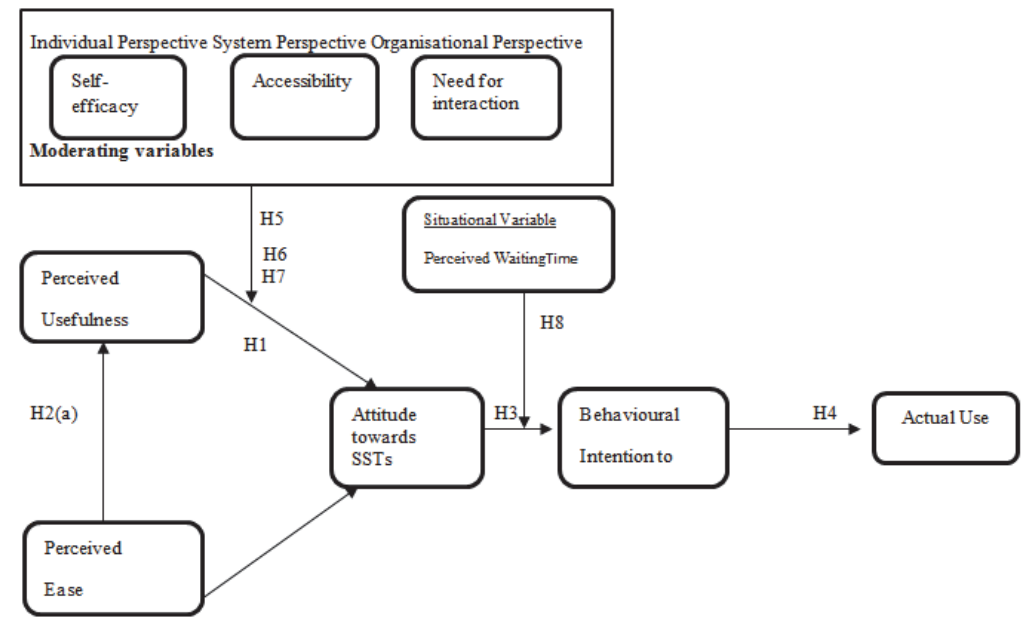

\section{Perceived Usefulness and Perceived Ease of Use}

From the original model, both perceived usefulness and perceived ease of use are belief constructs. Davis, Bagozzi andWarshaw (1989) defined perceived usefulness as the potential consumer's subjective chance that using a particular application system will increase his or her performance when executing a task in an organisational context. Perceived ease of use is the point at which the potential consumer has an expectation of the target system being free of effort (Davis, Bagozzi, \& Warshaw, 1989).

In most studies, perceived usefulness has been suitable for products such as computer software, but it is not very appropriate for technology-based self-service, where the consumer takes part in the service but is not the owner of the actual service (Dabholkar \& Bagozzi, 2002). As an alternative, an appropriate element which was extracted from Dabholkar's (1994) study was performance which came from the qualitative research and a definition of this concept was around the reliability and accuracy of the technology-based self-service, in the consumers' perspective. This research therefore recommends using these dimensions (ease of use and usefulness) to analyse the consumer's attitudes toward using SSTs at the University of the Witwatersrand.

Hypothesis 1: Perceived usefulness of the SST is positively related to attitude toward the SST.

Hypothesis 2a: Perceived ease of use has a positive impact on Perceived usefulness to use the SST.

Hypothesis 2b: Perceived ease of use positively influences the Attitude to use the SST. 


\section{Attitude towards SST}

Attitudinal research suggests that attitudes will have a strong, direct, and positive effect on intentions to use a self-service technology. This relationship between attitudes and intentions is essential in attitudinal research and has been maintained in various situations (Dabholkar \& Bagozzi, 2002).

Hypothesis 3: Attitude has a positive impact on Behavioural Intention to use the SST.

Hypothesis 4: Behavioural Intention to use the SST will have a positive effect on the Actual Use of the SST

\section{External Variables}

The model looks at the moderating variables which will be fragmented into different variables, namely: SST self-efficacy, need for interaction and accessibility to the SST. The function of external variables and the impacts it has on usage behaviour within the TAM has not been greatly explored. Davis (1993) particularly insisted on future research to look into the role of additional external variables within the TAM which this research aims to do as it derives different variables from the university context. TAM emphasises the fact that the influence of external variables on the consumers' behaviour towards the SST is decided on through consumer beliefs and attitudes (Hubona \& Geitz, 1997). Beliefs represent a measure of instrumentality or an amount of influence attached to an action while attitudes are simply affective and emotional. Beliefs are related to a person's subjective opinion that performing in a certain manner will ultimately have some sort of a consequence, while attitudes are linked to a person's positive or negative affective feelings about performing in this manner (Hubona \& Geitz, 1997).

\subsection{Moderating Variables}

Moderating effects which are also independent variables in the model include consumer traits and situational factors. The first variable is self-efficacy which is termed as a person's evaluation of his or her ability to execute a certain type of behaviour (Dabholkar \& Bagozzi, 2002). Some consumers may be more accustomed with using an SST system than other students which means their self-efficacy may be higher (Dabholkar \& Bagozzi, 2002).

Self-efficacy is a key factor that causes the essential motivation and it is then expected to indirectly influence behavioural intentions (Davis, Bagozzi, \& Warshaw, 1989). Consumers who have better self-efficacy are more likely to have an increased confidence in their ability to use an SST and as a result, ease of use and usefulness will not be as significant to them as to those consumers who have a reduced amount of confidence in their own abilities. Consumers with higher self-efficacy will tend to focus on the whether it is worthwhile to perform the service by using an SST and yet the sense of self-confidence in one's ability to do something makes it possible to look on that activity as useful. Therefore, with greater self-efficacy, the relationship between perceived usefulness and attitude will be strengthened.

Hypothesis 5: With greater self-efficacy the positive relationship between perceived usefulness and attitude toward using the SST will be weakened.

Another variable in the moderating effects is the need for interaction with a service employee. The need for interaction with a service employee can be described as the importance of human interaction to the customer during service encounters (Dabholkar,1996). For some consumers, the need for human contact in a service delivery is very essential for one to complete the service. If the need for interaction is great for consumers, they will avoid self-service, and those that are technology supported in particular, but if the need for interaction is quite small, consumers will make use of these SST options (Dabholkar \& Bagozzi, 2002).

Hypothesis 6: With greater need for interaction with a service employee the positive relationship between perceived usefulness and attitude toward using a SST will be strengthened.

Studies indicate that more accessibility to information results in the use of more information and an increased perception of ease of use (Lin \& Lu, 2000). SST accessibility is the level of ease through which a Wits student can access and use an SST system as an organisational factor (Park, 2009).

Hypothesis 7: With sufficient accessibility to SST at Wits, the positive relationship between perceived usefulness and attitude toward using a SST will be strengthened.

\subsection{Situational Variable}

Situational influence is an addition to the TAM. An appropriate situational variable for self-service is associated to waiting(Dabholkar \& Bagozzi, 2002). Various studies present the fact that consumers do not like to wait and this is the case with students, they do not want to waste their time in the waiting process (Dabholkar \& Bagozzi, 2002). SSTs are 
mostly selected as the preferred option maybe used when they are perceived as quicker than the conventional service method. Institutions have to understand the impact of perceived waiting time on SST systems, knowing that there is increase in the frequency of long lines and delays in such environments (Dabholkar \& Bagozzi, 2002).Time pressure, time of day, and location of the SST kiosks and access to the technology could be incorporated in the perceptions of waiting time (Dabholkar \& Bagozzi, 2002).

Hypothesis 8: With greater perceived waiting time, the positive relationship between attitude and intention toward using a SST will be weakened.

\section{Research Design and Methodology}

Quantitative research is a form of conclusive research.. This particular research methodology searches for ways to quantify the data numerically and frequently uses some type of statistical analysis to gather conclusions from the research (Malhotra \& Peterson, 2006).

\subsection{Primary Research}

\subsection{Sample}

Questionnaires were distributed to a sample of approximately 380 students at the University of the Witwatersrand (Wits University) in Johannesburg, South Africa. The sample included both male and female students who made use of the services on campus. The sampling that was used is the simple random sampling which is classified as probability sampling (Malhotra \& Peterson, 2006). Every unit has a known probability of being chosen.

\subsubsection{Research Design}

The research used a quantitative design. A cross-sectional design was used which is also known as a sample survey and can basically be thought of as instant shot of respondents being measured (Malhotra \& Peterson 2006).

\subsubsection{Data Gathering}

The questionnaire being put together was the first step that needed to be done. The layout of the questionnaires included a cover sheet explaining what the research was all about to the respondents, and within the actual questionnaire were different sections that would measure the different variables on the model that was being tested.

\subsubsection{Data Analysis}

A Likert scale was used in one section, where questions had five response alternatives: strongly disagree (1) disagree (2) neutral (3) agree (4) strongly agree (5). Combined responses from the series of questions created an attitudinal measurement scale (Malhotra \& Peterson, 2006).Other questions tested attitudes, preferences and behaviour. In analysing the overall data gathered from the questionnaires, the statistical software SAS Enterprise Guide 5.1 was used to perform the statistical analyses.

\section{Results}

\subsection{Reliability}

The composite reliability was estimated to assess the internal consistency of the measurement model. Table 1 summarises the reliability of the measurement tool. The composite reliabilities of the constructs included in the research model were between the range of 0.66 and 0.84 (see Table 1). All the main constructs have Cronbach's alpha above 0.6 which is acceptable which is greater than the suggested standard of 0.60 (Wu \& Wang, 2005). This shows that most of the measures had a strong and adequate reliability and discriminate above 0.7. 
Table 1: Cronbach's Alpha for the Main Constructs

\begin{tabular}{|lcc|}
\hline Main Constructs & Mean & Cronbach's Alpha \\
\hline Perceived Usefulness & 3.70 & 0.699313 \\
\hline Perceived Ease of Use & 3.59 & 0.844959 \\
\hline Attitude Towards SST & 4.04 & 0.732071 \\
\hline Behavioural Intention to use & 3.83 & 0.794657 \\
\hline Actual Use and Frequency & 3.56 & 0.748251 \\
\hline
\end{tabular}

The moderating variables which measure the effect on attitude are also above the suggested standard of 0.60 (Wu \& Wang, 2005), which mean they are reliable variables to use to conduct the research study. They are between the range of 0.66 and 0.80 .

Table 2: Cronbach's Alpha for the Moderating Variables

\begin{tabular}{|lcc|}
\hline Moderating Variables & Mean & Cronbach's Alpha \\
\hline Self-Efficacy & 3.97 & 0.745515 \\
\hline Need for interaction & 2.90 & 0.807384 \\
\hline Accessibility & 3.69 & 0.667380 \\
\hline Perceived Waiting Time & 3.98 & 0.732860 \\
\hline
\end{tabular}

\subsection{Perceived usefulness and Attitude}

The first linear regression analysis is examining the relationship between the perceived usefulness of the SSTs and the Attitude toward the SST. Below are the null and alternative hypotheses. SST.

The null hypothesis $(\mathrm{HO})$ is: Perceived usefulness of the SST is not significantly related to the Attitude toward the

The alternative hypothesis $(\mathrm{H} 1)$ is: Perceived usefulness of the SST is positively related to Attitude toward the SST.

Table 3 demonstrates the results of the linear regression analysis test for the Perceived usefulness and Attitude.

Table 3: Linear regression for the Perceived usefulness and Attitude towards the use of the SST

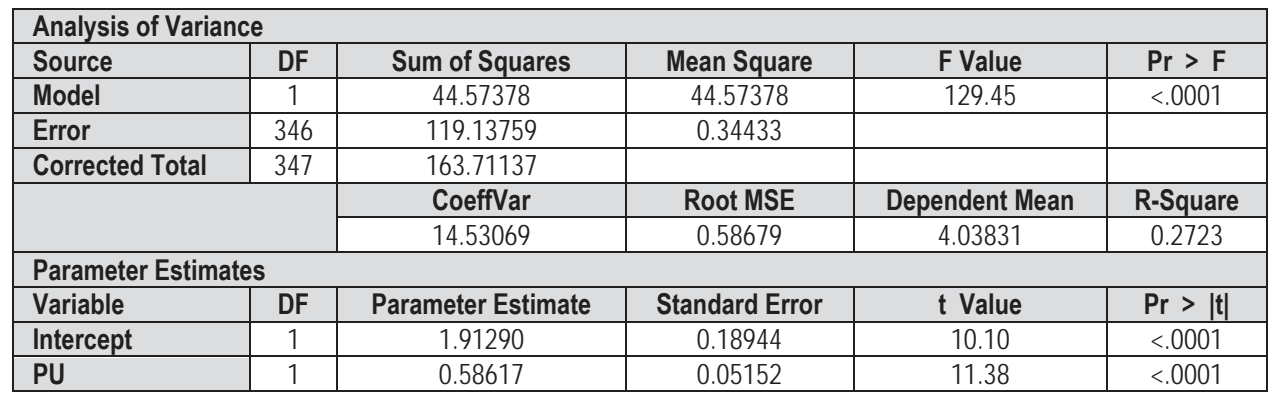

The $p$-value for the model test is $<0.0001$, this is lower than the significance level (a) of 0.05 .

This means that the model is significant and a good fit for the data. The $p$-value of the intercept is $<0.0001$; this is significant at both the 0.05 and 0.1 levels of significance. This means that the intercept is significant. The $p$-value for the perceived usefulness construct is $<0.0001$ this is significant at the 0.05 significance level. Therefore the researcher rejects the null hypothesis in favour of the alternative hypothesis which states that the Perceived usefulness of the SST is positively related to Attitude toward the SST. So the Perceived usefulness of the SST is significantly related to the Attitude toward the SST at Wits. 


\subsection{Perceived ease of use and Perceived usefulness}

The second linear regression analysis is examining the relationship between the Perceived ease of use and Perceived usefulness of the SST. Below are the null and alternative hypotheses.

The null hypothesis $(\mathrm{H} 0)$ is: Perceived ease of use is not significantly related to Perceived usefulness to use the SST.

The alternative hypothesis ( $\mathrm{H} 1)$ is: Perceived ease of use has a positive impact on Perceived usefulness to use the SST.

Table 4 demonstrates the results of the linear regression analysis test for the Perceived ease of use and Perceived usefulness of the SST

Table 4: Linear regression for the Perceived ease of use and Perceived usefulness of the SST.

\begin{tabular}{|c|c|c|c|c|c|}
\hline \multicolumn{6}{|c|}{ Analysis of Variance } \\
\hline Source & DF & Sum of Squares & Mean Square & F Value & $\operatorname{Pr}>\mathrm{F}$ \\
\hline Model & 1 & 28.92792 & 28.92792 & 99.30 & $<.0001$ \\
\hline Error & 346 & 100.80093 & 0.29133 & & \\
\hline Corrected Total & 347 & 129.72885 & & & \\
\hline & & CoeffVar & Root MSE & Dependent Mean & R-Square \\
\hline & & 14.88578 & 0.53975 & 3.62596 & 0.2230 \\
\hline \multicolumn{6}{|c|}{ Parameter Estimates } \\
\hline Variable & DF & Parameter Estimate & Standard Error & t Value & $\operatorname{Pr}>|t|$ \\
\hline Intercept & 1 & 2.24033 & 0.14203 & 15.77 & $<.0001$ \\
\hline PEOU & 1 & 0.38582 & 0.03872 & 9.96 & $<.0001$ \\
\hline
\end{tabular}

The $p$-value for the model test is $<0.0001$, this is lower than the significance level (a) of 0.05 .

This means that the model is significant and a good fit for the data. The $p$-value of the intercept is $<0.0001$; this is significant at both the 0.05 and 0.1 levels of significance. This means that the intercept is significant. The $p$-value for the perceived usefulness construct is $<0.0001$ this is significant at the 0.05 significance level. Therefore the researcher rejects the null hypothesis in favour of the alternative hypothesis which states that the Perceived ease of use has a positive impact on Perceived usefulness to use the SST. So the Perceived ease of use is significantly related to the Perceived usefulness to use the SST.

\subsection{Perceived ease of use and Attitude}

The third linear regression analysis is examining the relationship between the Perceived ease of use and Attitude towards the SST. Below are the null and alternative hypotheses.

The null hypothesis $(\mathrm{HO})$ is: Perceived ease of use is not significantly related to the Attitude to use the SST.

The alternative hypothesis $(\mathrm{H} 1)$ is: Perceived ease of use positively influences the Attitude to use the SST.

Table 5. demonstrates the results of the linear regression analysis test for the Perceived ease of use and Attitude towards the SST.

Table 5: Linear regression for the Perceived ease of use and Attitude towards the SST.

\begin{tabular}{|c|c|c|c|c|c|}
\hline \multicolumn{6}{|c|}{ Analysis of Variance } \\
\hline Source & DF & Sum of Squares & Mean Square & F Value & $\mathrm{Pr}>\mathrm{F}$ \\
\hline Model & Model & 1 & 24.72320 & 24.72320 & 61.55 \\
\hline Error & Error & 346 & 138.98817 & 0.40170 & \\
\hline Corrected Total & Corrected Total & 347 & 163.71137 & & \\
\hline \multirow{2}{*}{\multicolumn{2}{|c|}{ - }} & CoeffVar & Root MSE & Dependent Mean & R-Square \\
\hline & & 15.69462 & 0.63380 & 4.03831 & 0.1510 \\
\hline \multicolumn{6}{|c|}{ Parameter Estimates } \\
\hline Variable & DF & Parameter Estimate & Standard Error & $\mathrm{t}$ Value & $\operatorname{Pr}>|t|$ \\
\hline Intercept & 1 & 2.75734 & 0.16678 & 16.53 & $<.0001$ \\
\hline PEOU & 1 & 0.35668 & 0.04546 & 7.85 & $<.0001$ \\
\hline
\end{tabular}


The $p$-value for the model test is $<0.0001$, this is lower than the significance level (a) of 0.05 .

This means that the model is significant and a good fit for the data. The $p$-value of the intercept is $<0.0001$; this is significant at both the 0.05 and 0.1 levels of significance. This means that the intercept is significant. The $p$-value for the perceived ease of use construct is $<0.0001$ this is significant at the 0.05 significance level. Therefore the researcher rejects the null hypothesis in favour of the alternative hypothesis which states that the Perceived ease of use positively influences the Attitude to use the SST. So the Perceived ease of use is significantly related to the Attitude to use the SST.

\subsection{Attitude and the Behavioural Intention to use}

The fourth linear regression analysis is examining the relationship between the Attitude and the Behavioural Intention to use the SST. Below are the null and alternative hypotheses.

The null hypothesis $(\mathrm{HO})$ is: Attitude is not significantly related to the Behavioural Intention to use the SST.

The alternative hypothesis $(\mathrm{H} 1)$ is: Attitude has a positive impact on Behavioural Intention to use the SST.

Table 6 demonstrates the results of the linear regression analysis test for the Attitude and Behavioural Intention to use the SST.

Table 6: Linear regression for the Attitude and Behavioural Intention to use the SST.

\begin{tabular}{|c|c|c|c|c|c|}
\hline \multicolumn{6}{|c|}{ Analysis of Variance } \\
\hline Source & DF & Sum of Squares & Mean Square & F Value & $\operatorname{Pr}>F$ \\
\hline Model & 1 & 63.45351 & 63.45351 & 210.87 & $<.0001$ \\
\hline Error & 346 & 104.11373 & 0.30091 & & \\
\hline Corrected Total & 347 & 167.56724 & & & \\
\hline \multirow[t]{2}{*}{ 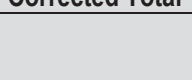 } & & CoeffVar & Root MSE & Dependent Mean & R-Square \\
\hline & & 14.33794 & 0.54855 & 3.82586 & 0.3787 \\
\hline \multicolumn{6}{|c|}{ Parameter Estimates } \\
\hline Variable & DF & Parameter Estimate & Standard Error & t Value & $\operatorname{Pr}>|t|$ \\
\hline Intercept & 1 & 1.31173 & 0.17561 & 7.47 & $<.0001$ \\
\hline ATT & 1 & 0.62257 & 0.04287 & 14.52 & $<.0001$ \\
\hline
\end{tabular}

The P-value for the model test is $<0.0001$, this is lower than the significance level (a) of 0.05 .

This means that the model is significant and a good fit for the data. The $p$-value of the intercept is $<0.0001$; this is significant at both the 0.05 and 0.1 levels of significance. This means that the intercept is significant. The $p$-value for the attitude construct is $<0.0001$ this is significant at the 0.05 significance level. Therefore the researcher rejects the null hypothesis in favour of the alternative hypothesis which states that the Attitude has a positive impact on Behavioural Intention to use the SST. So the Attitude is significantly related to the Behavioural Intention to use the SST.

\subsection{Behavioural Intention to use and Actual Use.}

The fifth linear regression analysis is examining the relationship between the Behavioural Intention to use and Actual Use the SST. Below are the null and alternative hypotheses. SST

The null hypothesis $(\mathrm{HO})$ is: Behavioural Intention to use the SST is not significantly related to the Actual Use of the

The alternative hypothesis ( $\mathrm{H} 1)$ is: Behavioural Intention to use the SST will have a positive effect on the Actual Use of the SST

Table 7 demonstrates the results of the linear regression analysis test for the Behavioural Intention to use and Actual Use the SST. 
Table 7: Linear regression for the Behavioural Intention to use and Actual Use the SST.

\begin{tabular}{|l|c|c|c|c|c|}
\hline Analysis of Variance \\
\hline Source & DF & Sum of Squares & Mean Square & F Value & Pr > F \\
\hline Model & 1 & 67.76832 & 67.76832 & 163.62 & $<.0001$ \\
\hline Error & 346 & 143.30693 & 0.41418 & & \\
\hline Corrected Total & 347 & 211.07525 & & & \\
\hline \multicolumn{7}{|l|}{} \\
\cline { 2 - 6 } & CoeffVar & Root MSE & Dependent Mean & R-Square \\
\hline Parameter Estimates & 18.07970 & 0.64357 & 3.55963 & 0.3211 \\
\hline Variable & DF & Parameter Estimate & Standard Error & t Value & Pr > $|\mathbf{t}|$ \\
\hline Intercept & 1 & 1.12659 & 0.19331 & 5.83 & $<.0001$ \\
\hline BI & 1 & 0.63594 & 0.04972 & 12.79 & $<.0001$ \\
\hline
\end{tabular}

The $p$-value for the model test is $<0.0001$, this is lower than the significance level (a) of 0.05 .

This means that the model is significant and a good fit for the data. The $p$-value of the intercept is $<0.0001$; this is significant at both the 0.05 and 0.1 levels of significance. This means that the intercept is significant. The $p$-value for the behavioural intention construct is $<0.0001$ this is significant at the 0.05 significance level. Therefore the researcher rejects the null hypothesis in favour of the alternative hypothesis which states that the Behavioural Intention to use the SST will have a positive effect on the Actual Use of the SST. So the Behavioural Intention is significantly related to the Behavioural Intention to use the SST.

\subsection{Moderating Variables}

\subsubsection{Perceived usefulness, attitude and self-efficacy.}

The first linear regression analysis which includes a moderating variable effect begins with an interaction between Selfefficacy and Perceived Usefulness to test the relationship with the Attitude towards the SST. Below are the null and alternative hypotheses.

The null hypothesis $(\mathrm{HO})$ is: Self-efficacy does not have a significant influence on the relationship between Perceived usefulness and attitude toward using the SST.

The alternative hypothesis $(\mathrm{H} 1)$ is: Self-efficacy positively influences the relationship between Perceived usefulness and attitude toward using the SST.

Table 8 demonstrates the results of the linear regression analysis test for the interaction between Self-efficacy and Perceived Usefulness to test the relationship with the Attitude towards the SST.

Table 8: Linear regression for the interaction between Self-efficacy and Perceived Usefulness to test the relationship with the Attitude towards the SST.

\begin{tabular}{|l|c|c|c|c|c|}
\hline Analysis of Variance & DF & Sum of Squares & Mean Square & F Value & Pr > F \\
\hline Source & 3 & 58.00572 & 19.33524 & 62.92 & $<.0001$ \\
\hline Model & 344 & 105.70565 & 0.30728 & & \\
\hline Error & 347 & 163.71137 & & & \\
\hline Corrected Total & CoeffVar & Root MSE & Dependent Mean & R-Square \\
\hline \multicolumn{7}{|l|}{} \\
\cline { 2 - 6 } \\
\cline { 2 - 6 } \\
\hline \multicolumn{7}{|l|}{ Parameter Estimates } \\
\hline Variable & 13.72681 & 0.55433 & 4.03831 & 0.3543 \\
\hline Intercept & 1 & -0.27352 & 1.09663 & -0.25 & 0.8032 \\
\hline SE*PU & 1 & -0.08805 & 0.07379 & -1.19 & 0.2336 \\
\hline PU & 1 & 0.93740 & 0.29909 & 3.13 & 0.0019 \\
\hline SE & 1 & 0.54048 & 0.27487 & 1.97 & 0.0501 \\
\hline
\end{tabular}

The $p$-value of the interaction term (Self-Efficacy*Perceived Usefulness) is non-significant which means the interaction between perceived usefulness and Self-Efficacy does not have a significant effect on the response variable "attitude". 
Which means the regression can be run without the interaction effect and keep only the main effects in (Perceived Usefulness and Self-Efficacy). Self-Efficacy is just not significant at the $5 \%$ level but it is significant at the $10 \%$ level of significance. Thus the main effects (variables Self-Efficacy and Perceived Usefulness) have a significant effect on Attitude and both of them have a positive beta regression coefficient estimate values which means there is a significant positive linear relationship between the two main effects and attitude.

The $p$-value for the perceived usefulness construct is 0.0019 being significant and for the Self-Efficacy construct is 0.0501 this is insignificant at the 0.05 significance level. The interaction between Self-Efficacy and Perceived Usefulness has a p-value which is 0.2336 therefore the researcher fails to reject the null hypothesis which states that with greater self-efficacy the positive relationship between perceived usefulness and attitude toward using a SST will be weakened.

\subsubsection{Perceived usefulness, attitude and accessibility.}

The second linear regression analysis which includes a moderating variable effect begins with an interaction between Accessibility and Perceived Usefulness to test the relationship with the Attitude towards the SST. Below are the null and alternative hypotheses.

The null hypothesis $(\mathrm{HO})$ is: Accessibility does not have a significant influence on the relationship between Perceived usefulness and attitude toward using the SST.

The alternative hypothesis $(\mathrm{H} 1)$ is: Accessibility positively influences the relationship between Perceived usefulness and attitude toward using the SST.

Table 5.24 demonstrates the results of the linear regression analysis test for the interaction between Accessibility and Perceived Usefulness to test the relationship with the Attitude towards the SST.

Table 9: Linear regression for the interaction between Accessibility and Perceived Usefulness to test the relationship with the Attitude towards the SST.

\begin{tabular}{|l|c|c|c|c|c|}
\hline Analysis of Variance & DF & Sum of Squares & Mean Square & F Value & $\operatorname{Pr}>$ F \\
\hline Source & 3 & 55.81775 & 18.60592 & 59.32 & $<.0001$ \\
\hline Model & 344 & 107.89362 & 0.31364 & & \\
\hline Error & 347 & 163.71137 & & & \\
\hline Corrected Total & CoeffVar & Root MSE & Dependent Mean & R-Square \\
\hline \multicolumn{5}{|l|}{} \\
\cline { 2 - 6 } \\
\cline { 2 - 6 } \\
\hline \multicolumn{7}{|l|}{ Parameter Estimates } & 13.86815 & 0.56004 & 4.03831 & 0.3410 \\
\hline Variable & DF & Parameter Estimate & Standard Error & t Value & Pr > |t $\mid$ \\
\hline Intercept & 1 & 0.85356 & 0.92239 & 0.93 & 0.3554 \\
\hline PU & 1 & 0.68894 & 0.24929 & 2.76 & 0.0060 \\
\hline ACC & 1 & 0.27184 & 0.24900 & 1.09 & 0.2757 \\
\hline ACC*PU & 1 & -0.02680 & 0.06590 & -0.41 & 0.6845 \\
\hline
\end{tabular}

The $p$-value of the interaction term (Accessibility*Perceived Usefulness) is non-significant which means the interaction between Perceived Usefulness and Accessibility does not have a significant effect on the response variable "attitude". Which means the regression can be run without the interaction effect and keep only the main effects in (perceived usefulness and Accessibility). Accessibility is just not significant at the $5 \%$ level. Thus the main effect (variables perceived usefulness) has a significant effect on Attitude. There is a significant positive linear relationship between perceived usefulness and attitude.

The $p$-value for the perceived usefulness construct is 0.0060 being significant and the accessibility construct is 0.2757 this is insignificant at the 0.05 significance level. The interaction between Accessibility and Perceived Usefulness has a p-value which is 0.6845 therefore the researcher fails to reject the null hypothesis which states that with sufficient accessibility to SST at Wits, the positive relationship between perceived usefulness and attitude toward using a SST will be strengthened.

\subsubsection{Perceived usefulness, attitude and the need for interaction.}

The third linear regression analysis which includes a moderating variable effect begins with an interaction between the 
Need for Interaction and Perceived Usefulness to test the relationship with the Attitude towards the SST. Below are the null and alternative hypotheses.

The null hypothesis $(\mathrm{H} 0)$ is: The Need for Interaction does not have a significant influence on the relationship between Perceived usefulness and attitude toward using the SST.

The alternative hypothesis $(\mathrm{H} 1)$ is: The Need for Interaction positively influences the relationship between Perceived usefulness and attitude toward using the SST.

Table 10 demonstrates the results of the linear regression analysis test for the interaction between The Need for Interaction and Perceived Usefulness to test the relationship with the Attitude towards the SST.

Table 10: Linear regression for the interaction between the Need for Interaction and Perceived Usefulness to test the relationship with the Attitude towards the SST.

\begin{tabular}{|c|c|c|c|c|c|}
\hline \multicolumn{6}{|c|}{ Analysis of Variance } \\
\hline Source & DF & Sum of Squares & Mean Square & F Value & $\operatorname{Pr}>\mathrm{F}$ \\
\hline Model & 3 & 52.71216 & 17.57072 & 54.45 & $<.0001$ \\
\hline Error & 344 & 110.99920 & 0.32267 & & \\
\hline Corrected Total & 347 & 163.71137 & & & \\
\hline \multirow[t]{2}{*}{ (t) } & & CoeffVar & Root MSE & Dependent Mean & R-Square \\
\hline & & 13.86815 & 0.56004 & 4.03831 & 0.3410 \\
\hline \multicolumn{6}{|c|}{ Parameter Estimates } \\
\hline Variable & DF & Parameter Estimate & Standard Error & t Value & $\operatorname{Pr}>|t|$ \\
\hline Intercept & 1 & 1.99733 & 0.62101 & 3.22 & 0.0014 \\
\hline PU & 1 & 0.62886 & 0.16429 & 3.83 & 0.0002 \\
\hline INT & 1 & -0.12050 & 0.20437 & -0.59 & 0.5558 \\
\hline INT*PU & 1 & 0.00579 & 0.05477 & 0.11 & 0.9159 \\
\hline
\end{tabular}

The p-value of the interaction term (Need for Interaction*Perceived Usefulness) is non-significant which means the interaction between Perceived Usefulness and Need for Interaction does not have a significant effect on the response variable "attitude". Which means the regression can be run without the interaction effect and keep only the main effects in (perceived usefulness). Need for Interaction is not significant at the $5 \%$ level. The main effect (variables Perceived Usefulness) has a significant effect on Attitude. There is a significant positive linear relationship between perceived usefulness and attitude.

The $p$-value for the model test is $<0.0001$, this is lower than the significance level (a) of 0.05 .

This means that the model is significant and a good fit for the data. The $p$-value of the intercept is 0.0014 ; this is significant at both the 0.05 and 0.1 levels of significance. This means that the intercept is significant. The $p$-value for the perceived usefulness construct is 0.0002 being significant and the need for interaction construct is 0.5558 this is insignificant at the 0.05 significance level. The interaction between Need for Interaction and Perceived Usefulness has a p-value which is 0.9159 therefore the researcher fails to reject the null hypothesis which states that with greater need for interaction with a service employee the positive relationship between perceived usefulness and attitude toward using a SST will be strengthened.

\subsection{Situational Variable}

\subsubsection{Attitude, behavioural intention and perceived waiting time.}

The linear regression analysis which includes a situational variable effect begins with an interaction between the perceived waiting time and attitude towards the SST to test the relationship with the behavioural intention to use the SST. Below are the null and alternative hypotheses.

The null hypothesis $(\mathrm{HO})$ is: With greater perceived waiting time, there is no significant relationship between attitude and behavioural intention toward using the SST.

The alternative hypothesis ( $\mathrm{H} 1)$ is: With greater perceived waiting time, there is a positive relationship between attitude and behavioural intention toward using the SST.

Table 11 demonstrates the results of the linear regression analysis test for the interaction between perceived waiting time and attitude to test the relationship with the behavioural intention towards the SST. 
Table 11: Linear regression for the interaction between Perceived Waiting Time and Behavioural Intention to test the relationship with the Actual Use of the SST.

\begin{tabular}{|l|c|c|c|c|c|}
\hline Analysis of Variance & DF & Sum of Squares & Mean Square & F Value & Pr $>$ F \\
\hline Source & 3 & 70.82979 & 23.60993 & 83.96 & $<.0001$ \\
\hline Model & 344 & 96.73745 & 0.28121 & & \\
\hline Error & 347 & 167.56724 & & & R-Square \\
\hline Corrected Total & CoeffVar & Root MSE & Dependent Mean & 0.4227 \\
\hline \multicolumn{7}{|l|}{} \\
\cline { 2 - 6 } \\
\hline Parameter Estimates & 13.86082 & 0.53030 & 3.82586 & Pr > $|\mathbf{t}|$ \\
\hline Variable & DF & Parameter Estimate & Standard Error & t Value & 0.0055 \\
\hline Intercept & 1 & 2.74303 & 0.98260 & 2.79 & 0.3605 \\
\hline PWT & 1 & -0.23414 & 0.25569 & -0.92 & 0.9031 \\
\hline ATT & 1 & -0.03078 & 0.25268 & -0.12 & 0.0391 \\
\hline ATT*PWT & 1 & 0.13054 & 0.06302 & 2.07 & \\
\hline
\end{tabular}

The p-value of the interaction term (Attitude*Perceived Waiting Time) is significant which means the interaction between Attitude and Perceived Waiting Time has a significant effect on the response variable "behavioural intention". Perceived Waiting Time and Attitude are both not significant at the 5\%, thus the main effects (variables Perceived Waiting Time and Attitude) do not have a significant effect on behavioural intention.

The $p$-value for the model test is $<0.0001$, this is lower than the significance level $(a)$ of 0.05 .This means that the model is significant and a good fit for the data. The p-value of the intercept is 0.0055 ; this is significant at both the 0.05 and 0.1 levels of significance. This means that the intercept is significant. The p-value for the Perceived Waiting Time construct is 0.3605 being insignificant and the Attitude construct is 0.9031 this is insignificant at the 0.05 significance level. The interaction between Attitude and Perceived Waiting Time has a p-value which is 0.0088 this is significant at the 0.05 significance level. Therefore the researcher rejects the null hypothesis in favour of the alternate hypothesis which states that with greater perceived waiting time, the positive relationship between attitude and intention toward using a SST will be weakened.

\section{Main Findings}

Figure 1: The Revised Technology Acceptance Model

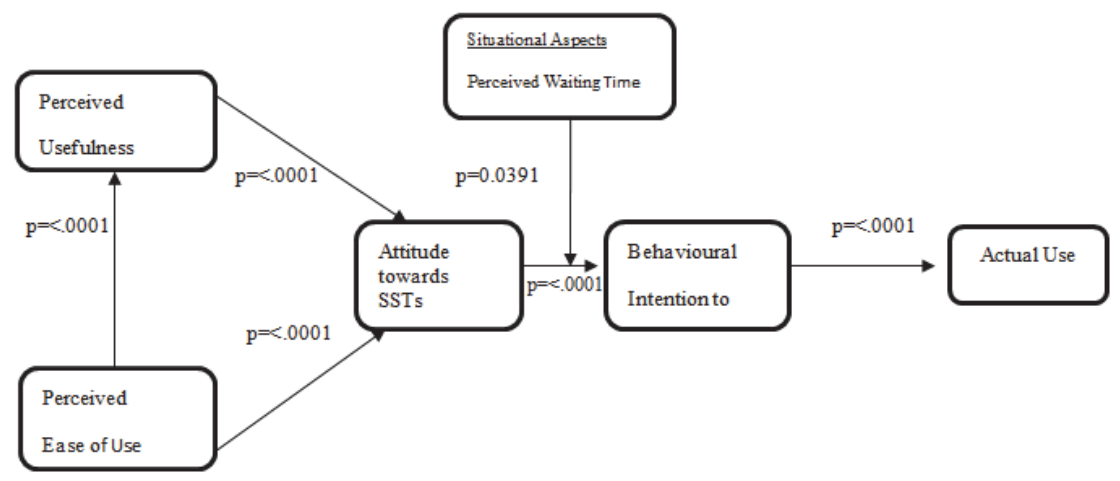

\subsection{Research Model}

The TAM that includes the p-values Figure 1 shows that all the linear regression relationships are all equally significant predictors for the effectiveness of SSTs at Wits.

The results shows that of the five hypotheses tested for the linear regression were all supported. Consistent with previous studies, perceived usefulness and perceived ease of use were found to be significant factors influencing the adoption to SSTs. An advantage of using TAM models is that they have been extensively tested and validated and are 
widely accepted models which can be modified or extended using other theories or constructs (Taylor \& Todd, 1995b; Davis \& Venkatesh, 2000; Wu \& Wang, 2005; Lin \& Hsieh, 2007). This study was able to confirm the applicability of TAM, in particular the perceived usefulness construct on the effectiveness of self-service technology. Further, this study was able to identify the important role that the moderating and situational variables played with regard to the attitude that students had toward SST and their behavioural intention to use them and in turn whether the SSTs are truly effective at Wits.

The main research question has been answered being: is the self-service technology system at the University of the Witwatersrand effective? Yes it is, but just how effective is it the SST. The linear technology acceptance model proved to be significant in measuring how well the consumers adapt to the SST but the moderation variables; selfefficacy, accessibility and need for interaction had an insignificant relationship when interacting with the perceived usefulness to have a look at the effect this relationship has on the attitude towards the SST. The hypothesis are analysed as well as the objectives.

The first finding was that perceived usefulness of the SST is positively related to attitude toward the SST. From the questions which were tested in the questionnaire, this means that consumers believe that SSTs improve their performance and productivity on campus and that using the SST is generally the best way to perform all services on campus. An example of a useful service that they conduct is borrowing books from the library. Consumers generally have a positive attitude towards SSTs and feel that that it is an advantageous way to perform a service and will be to consumers own benefit, the like the idea of working with this SST system.

The second finding being that the perceived ease of use has a positive impact on perceived usefulness to use the SST. The results of significance proves that when consumers know what is expected of them when using the SST, when they feel certain about how to use it, have control over the SST and generally find it easy to use the SST, they will find the SST useful for their lives.

This third finding which is perceived ease of use positively influences the attitude to use the SST. The results of significance proves that when consumers know what is expected of them when using the SST, when they feel certain about how to use it, have control over the SST and generally find it easy to use the SST they will have a positive attitude towards the SST.

The fourth finding is that the attitude towards the SST has a positive impact on behavioural intention to use the SST. The findings proved that when consumers believe that the SST is advantageous and beneficial to them and like the idea of using the SST at Wits, there will be a higher influence on the consumer's intention to make use of the SST on campus.

The fifth finding is that the behavioural intention to use the SST will have a positive effect on the actual use and frequency of the SST. The results prove that when consumers have a positive behavioural intention to use the SST on campus, are willing to introduce the system to other people and intend on using the SST when there is an improvement in the SST and access to a variety of additional services, more consumers will use the SST and at a higher frequency.

The next finding is one that includes a moderating variable, when self-efficacy positively influences the relationship between Perceived usefulness and attitude toward using the SST. The results indicate that there is an insignificant relationship and this could possibly mean that self-efficacy does not have a positive relationship towards the perceived usefulness or does not affect that relationship with the attitude towards the SST. Meaning consumers' confidence in their ability towards the SST, their experience with other SSTs, or consumers experience with the internet has a negative relationship actually meaning that with a lower self-efficacy, consumers will have a negative attitude towards the SST.

The next finding is one that includes a moderating variable, when the need for interaction positively influences the relationship between Perceived usefulness and attitude toward using the SST. The results indicate that there is an insignificant relationship and this could possibly mean that the need for interaction does not have a positive relationship towards the perceived usefulness or does not affect that relationship with the attitude towards the SST. Meaning consumers need for personal attention, contact and face to face interaction has a negative influence actually meaning that with the need for interaction, consumers will have a negative attitude towards the SST. When consumers have a neutral need for interaction or do not find it important, they will have a greater attitude towards SSTs.

The next finding is one that includes a moderating variable, when the accessibility positively influences the relationship between Perceived usefulness and attitude toward using the SST. The results indicate that there is an insignificant relationship and this could possibly mean that the accessibility does not have a positive relationship towards the perceived usefulness or does not affect that relationship with the attitude towards the SST. Meaning consumers access to the SST system from home and anywhere off campus, if they have opportunities to use the SST at any time on campus and if they experience difficulty using the SST when they are on campus results in a negative influence, actually meaning that with the lower accessibility, consumers will have a negative attitude towards the SST. When consumers 
have a neutral accessibility or do not find it important to have access, they will have a greater attitude towards SSTs.

With greater perceived waiting time, there is a positive relationship between attitude and behavioural intention toward using the SST.

Ultimately from the results observed, there is a need for SSTs at the Wits campus. Most of the students at Wits who act as consumers use the internet every day, approximately $88.51 \%$ of students. This should be an opportunity for Wits to have all students using the SST on a regular basis but on the contrary, no all $88.51 \%$ of these students use SST system and some do not have much knowledge on the extent of which they can perform services on the internet or without aid of an employee face-to-face.

The overall attitude that students have towards SSTs are that they seek an easy to use service that will benefit them and will be convenient at any location or the closest location in which they mostly find themselves. The lifestyle that the average consumer lives iis one where they do not have time to stand in long queues or they would rather optimise their time doing something else, even if that means spending time with a friend. Another important point is to note that not all the students are from around campus so whether it is during the school term or during holidays they would value a SST system that allows them to check their results or even perform the whole registration process to save costs and time.

\section{Recommendations and Managerial Implications}

The aim of marketing managers should be to create a more effective SST in order to have satisfied consumers. When students apply to university institutions, they consider technology operations such as this SST, at times it is a conscious decision and in other situations the decision may be influenced. During the registration period, most students cannot bear standing in long queues or being in dangerous overcrowding situations where they would need to be in an uncomfortable position to get through their registration process. An effective SST is needed here to avoid this situation.

In the case of the moderating variables, Wits has to take it upon themselves to inform students who are the main users of this system exactly how to use it and where they can make access of the service. Training classes or session would be extremely helpful. More step by step guides should be placed on printed posters or can be in the form of an easy to access program when logging on to school programs. Lab assistants can be trained to a greater extent to guide students through every process that will help them perform the SST more efficiently and students will have a greater selfefficacy.

Wits will have to improve SST system it offers towards students as majority of students indicated that they would frequently use the SST if they could register online, book meals, check their academic results at anytime of the year and not only in December and if they could load credit on their cards online as opposed to making their way to a kudu bucks terminal. These were the main drivers that would increase the frequency of use. Students would also like SSTs that are customised to their own personal needs and more reliable and faster systems. The ICAM department at Wits is currently working on making improvements, but with the technological changes taking place around the world, students need an up-to-date SST system. A system that is freely accessible to all students at various locations and one that will fill the faceto-face service encounter gap is what the student truly needs to have an effective form of self-service.

\section{Limitations and Future Research}

The moderation variables in this study are not the only effects that influence the students' attitudes towards the SSTs and future research can look at more effects at a broader scale. A limitation was that the technology acceptance model was structured in way that only a few constructs could be analysed and future research could incorporate more variables such as students' intrinsic and extrinsic influences to use SSTs or any brand or consumer identity constructs could be explored.

The effect of demographic variables such as race, age, gender and culture on adoption of SSTs in a university environment was not intensively explored. Some demographic variables may have indirect interrelation effects between the variables, for example according the cognitive propensity of individuals to self-efficacy differs across culture. This means that the customers' acceptance to SSTs may possibly be influenced by cultural differences. This phenomenon may require further investigation on a wider scale across various racial groups with cultural differences.

Another opportunity for future research could be a view of first year students who have recently moved from a different environment whether it be secondary education, taking a gap year or coming straight from the working environment and entering the university environment and how these different groups adopt the SSTs and how effect the SST system is across these various groups. 


\section{Conclusion}

This research study successfully assessed the effectiveness of SSTs at the University of the Witwatersrand. Perceived ease of use and perceived usefulness proved to have a positive influence on students' attitudes towards the SSTs. Moderating variables and the situational variable indicated the influence that external variables have on the attitude towards SSTs.

This research included a complete literature review and also carried out an empirical quantitative research study into the effectiveness of SSTs at the University of the Witwatersrand. The study looked at various descriptive analysis and the various factors that influence the adoption of SSTs by students at Wits. From the findings of the statistical analysis of the data collected, a conclusion is made that SSTs are effective to use at Wits, but considering the factors that affect its widespread use which leaves a gap of improvement.

With the growth of technology and the perceptions that students have towards SSTs and the way in which institutions perform their services, the effectiveness of SSTs and other technological services have so much room for improvement.

\section{References}

Berry, L. L., Seiders, K., \& Grewal, D. (2002). Understanding Service Convenience. Journal of Marketing, 66 (3), 1-17.

Bitner, S., Ostrom, A. L., \& Meuter, M. L. (2002), Implementing Successful Self-service Technologies. Academy of Management Executive, 16(4), 96-109.

Browne, B. A., Kaldenberg, D. O., Browne, W. G., \& Brown, D. J. (1998). Student as Customer: Factors Affecting Satisfaction and Assessments of Institutional Quality. Journal of Marketing for Higher Education , 8 (3), 1-14.

Curran, J.M., \& Meuter, M. L. (2005). Self-service technology adoption: comparing three technologies, Journal of Services Marketing, 19 (2), $103-113$.

Dabholkar, P. A. (1994). Incorporating Choice Into an Attitudinal Framework: Analyzing Models of Mental Comparison Processes. Journal of Consumer Research , 21, 100-118.

Dabholkar, P. A. (1996). Consumer Evaluations of New Technology-Based Self-Service Options: An Investigation of Alternative Models of Service Quality. International Journal of Research in Marketing , 13 (1), 29-51.

Dabholkar, P. A., \& Bagozzi, R. P. (2002). An Attitudinal Model of Technology-Based Self - Service: Moderating Effects of Consumer Traits and Situational Factors. Journal of the Academy of Marketing Science. , 30 (3), 184-201.

Davis, F. D. (1985). A technology acceptance model for empirically testing new end-user information systems: theory and results. Unpublished Doctoral dissertation, MIT Sloan School of Management.

Davis, F. D. (1989). Perceived usefulness, perceived ease of use, and user acceptance information technology. MIS Quarterly , 13 (3), 319-340.

Davis, F. D. (1993). User acceptance of information technology: System characteristics, user perceptions and behavioural impacts. International Journal of Man-Machine Studies , 38, 475-487.

Hubona, G. S., \& Geitz, S. (1997). External Variables, Beliefs, Attitudes and Information Technology Usage Behavior. The Thirtieth Annual Hawwaii International Conference on Social Sciences (pp. 1060-3425). Hawwaii: IEEE Computer Society.

Kgosana, V. (2013). ASAWU Report, 14 March.

Lin, J. C., \& Hsieh, P. (2007).The influence of technology readiness on satisfaction and behavioral intentions toward self-service technologies. Computers in Human Behavior , 23 (3), 1597-1615.

Malhotra, N. \& Peterson, M., (2006). Basic Marketing Research: A Decision-Making Approach, second edition. New Jersey: Pearson Prentice Hall.

Meuter, M. L., Bitner, M. J., Ostrom, A. L.,\& Brown, S. W. (2005). Choosing among Alternative Service Delivery Modes: An Investigation of Customer Trial of Self-Service Technologies.Journal of Marketing, 69, (2), 61-83.

Oliva, R., \& Kallenberg, R. (2003). Managing the transition from products to services. International Journal of Service Industry Management, 14 (2), 160-172.

Taylor, S., \& Todd, P. (1995). Understanding information technology usage: a test of competing models',. Information Systems Research $, 6,144-76$.

Davis, F. D. \& Venkatesh, V. (2000). A Theoretical Extension of the Technology Acceptance Model: Four Longitudinal Field Studies. Management Science , 46 (2), 186-204.

Wu, J. H., \& Wang, S. C. (2005). What drives mobile commerce?:: An empirical evaluation of the revised technology acceptance model. Information \&Management , 42 (5), 719-729. 